1000

\section{RENAL TUBULAR FUNCTION IN MINOR THALASSEMIA}

\section{S. Sadeghi-Bojd ${ }^{1}$, M. Hashemi²}

${ }^{1}$ Pediatric, ${ }^{2}$ Pediatric Nephrology, Zhedan Medical Sciences of University, Zahedan, Iran

$\beta$ - Thalassemia minor is a common heterozygous hemoglobinopathy that is characterized by both microcytosis and hypochromia. It has been postulated that low grade hemolysis, tubular iron deposition and toxins derived from erythrocytes might cause renal tubular damage in adult patients with $\beta$ - thalassemia minor.

The aim of this study is to investigate the renal tulbar function in children with $\beta$ - thalassemia minor and to determine its possible harmful effects.

\section{Methods:}

The study was conducted on 50 children (22 male and 28 female) at the age of years (range 4-19 years) with $\beta$ - Thalassemia minor. A control group was formed with 50 healthy children whose ages and sexes match those in the first group.

Blood and 24-hour urine samples were obtained for hematologic and biochemical analysis.

Results: There was statistically significant difference among the two groups in terms of the results of $\mathrm{FE}_{\mathrm{UA}}(\%)$, TPR $(\%), \mathrm{FE}_{\mathrm{k}}(\%)$, GFR, Urine uric Acid , serum Mg (P<0/05). But other significant signs of renal tubulopathy such as hypercalciuria , and tubular proteinuria $\left(\beta_{2}\right.$ - microglobolinuria) were not seen.

\section{Conclusion:}

On the contrary of children with $\beta$ - Thalassemia major, renal tubular dysfunction is not common in children with $\beta$ - Thalassemia minor.

.Alsow it suggested that in future studies to confirm renal tubular disfanction should be considered specific test such as NAG measurement and specific parameter of oxidative stress such as urin zinc level (indirect evidence of oxidative stress).
1001

PROCALCITONON AS EARLY MARKER IN UPPER URINARY TRACT INFECTION

\author{
S. Sadeghi-Bojd ${ }^{1}$, M. Hashemi ${ }^{2}$
}

${ }^{1}$ Pediatric Nephrology, ${ }^{2}$ Biochemistry, Zahedan Medical Sciences of University, Zahedan, Iran

in order to stablish the most reliable marker for distinguishing urinary tract infection,we recorderd the clinical features and admission lukocyte count ,ESR,CRPand procalcitoninin80 childrenaged2 mounth-10 years admitted with a first episod of UTI. Fifty children with mean age 4/89with 30 children with mean age 5/20 were compared.ESR,WBCand PCTbut no CRP were significantly higher in patient with upper UTI.( $p<0 / 0001)$.PCThad the best performance $(0 / 5 \mathrm{ng})$ with sensivity , spesifity and positive and negative predictive value of $\% 63, \% 8$ $3 / 3, \% 87 / 8$ and564/1respectively.PCTcutt of value 2ng/mlalso had sensivity, spesifity and positive and negative vale of $\% 50, \% 96 / 6, \% 96 / 2$ and $\% 53 / 7$ respectively.PCT was more sensitive and specific for the diagnosis of upperversus lower urinary tract infectionthan CRP.serumPCT is abetter marker than CRP for early prediction of pyelonephritis in children with a first epuisode of UTI.

\section{2}

\section{PULSE CYCLOPHOSPHAMIDE THERAPY FOR STEROID-RESISTANT FOCAL SEGMENTAL GLOMERULOSCLEROSIS IN CHILDREN}
A. Sharipov, K. Khamzayev, B. Mamatkulov

Pediatric Nephrology, Tashkent Pediatric Medical Institute, Tashkent, Uzbekistan

Background: In children, steroid-resistant nephritic syndrome due to focal segmental glomerulosclerosis (FSGS) is frequently a progressive condition resulting in end-stage renal disease (ESRD). We report the response of 25 patients with steroid resistant FSGS to treatment with intravenous pulse cyclophosphamide. Seven patients had initial steroid resistance and eighteen patients had late steroid resistance.

Materials and Methods: All patients were treated with with intravenous pulse cyclophosphamide at a dose of $20 \mathrm{mg} / \mathrm{kg} / \mathrm{month}$ for 12 months. Peroral prednisolone was given at a dose of $60 \mathrm{mg} / \mathrm{m} 2 /$ day for 6 weeks followed by $40 \mathrm{mg} / \mathrm{m} 2 /$ on alternate days for 6 weeks and then tapered over next 6 weeks. 